\title{
OPTIMIZATION OF THE DEHYDRATION OF MUDS IN PURIFIER STATIONS OF RESIDUAL WATERS BY MEANS OF THE EMPLOYMENT OF PHOTOTHERMIC ENERGY
}

\author{
Alfonso Jesús Herrera Torres, Antonio Espín Estrella \\ University of Granada \\ Phones: +34 958270081, +34 629485123; e-mail: alfonsojht@ hotmail.com
}

\begin{abstract}
Due to desired engagement with environmental enhance improvement, in these papers a new proposal is described and justifies for giving solution to the residual water depuration proceeding mud's quantity problem through a Clean Energy.
\end{abstract}

On sustained development, nowadays, we must take into account Alternative and Renewable Energies, by their eminent meaning. Besides, a growing problem also acquires importance like is the treatment of urban residues coming fro $\mathrm{m}$ water depuration.

Many parts take place in a Purifier Station, but this study is centred in the dehydration system, which takes charge of mostly decreasing of mud quantity.

Since the conviction of future increasing limitation of any kind of mud pouring places and the places where mud is used to refill lands, it is bet for the generation reduction and volume decreasing.

Key words : Collector, dehydration, mud, photothermic, purifier station, solar.

\section{Introduc tion}

In whole Europe some laws have entered in action for regulation, and in many cases for forbidding, of mud's dumping, and due to that methods of mud's reduction and odourless and easily handling material elaborating process methods (for cremation or other independent process designed for exploitation) have a new interest.

Current tendencies relating to urban mud's volume are driven to an almost complete reusage of black water's mud (compost production, energy generation, and even utilization for supplement feeds, after sterilization).

The reduction of Mud's production must be done in two ways:

- Driving adequately the purifier station.

- Thinking what mud is, a resource and keeping it carefully as something that can be used, not something in excess.
Now, in residual water purifier stations a mud's volume reduction process by its dehydration is been performing. The dehydration process is very expensive and sometimes profits are not very good, that is why this investigation also worries about the solution must include the very important economic factor.

There are three general methods for mud's dehydration (simply by sedimentation, mechanical and thermical) but a thermic dehydration system has been chosen, because resides in apply heat for a drying process, and nowadays efficient results based on heat attainment using photothermic systems .

Mud is dehydrated in a closed recipient applying any heating process at a temperature that prevents an important decomposition of principal constituents, and so be able to get the volume reduction target and volatile odoriferous components evaporation.

Different methods can be used:

- Direct dry, which makes mud be in close contact with overheated water steam, or hot air, which also works as transport environ for mud.. Heat transfer is high.

- Indirect dry, in which mud and heat source are separate. Mud flows through a drier surface, by agitation or scraping. Calorific transfer is less efficient and smaller air volumes are used, which require a treatment for extract the smell.

Taking this into account, we thought to follow a investigation line to give coherent and feasible solutions which, full of environmental sensibility, place imagination and work at people's service to have a cleaner environ and where resources we have be used in a efficient way, for subproducts on a human intervention process (mud) and which directly give us Nature (Solar Energy.

\section{Objectives}

Control and use of Renewable Energies are very important for a sustained development, so we thought to supply an idea which includes both themes. 
For theoretical testing of the new proposed system functioning, this study will be applied to real data corresponding to a population of 80.000 citizens aprox., such as Melilla, where nowadays there is a purifier station enhanced with a mechanical dehydration system through centrifugation.

Although the real proposal involves a simultaneity between both systems through a hypothetical solar insufficiency for several days which makes us to use the centrifugator, even though we could choose a mixed thermic and mechanical drier system which makes us to get a higher dried matter percentage, it will suppose a theoretical substitution of centrifugation system by the thermic drying system using solar energy.

The final idea of the dehydration process is to make possible to feed a cremation plant using resulting mud or, thinking back in Renewable Energies, a biomass energy generation system which will provide us again new energetic reusage.

\section{Investigation's development}

The initial idea was the usage of remaining heat form a phototermic installation into a oven or dehydration place where to dump the mud that currently flows to the centrifugator of current installation, and evacuate from the oven the drying mud using transporting bands.

At first sight, someone could think to increase the mud's temperature at $100^{\circ} \mathrm{C}\left(373^{\circ} \mathrm{K}\right)$ to produce the contained water boiling, but for not to get problems on collector proceeding fluid by burbles generation (cavitation problems), we would need to put this fluid at pressure higher than atmospheric. To prevent extra costs due to the last situation, we thought to increase mud's temperature at $95^{\circ} \mathrm{C}\left(368^{\circ} \mathrm{K}\right)$.

According to this we could make the following question: How could mud be able to boil if the temperature is not $100^{\circ} \mathrm{C}$ ? It is known that at normal pressure and a $\mathrm{t}$ sea level, water boils at $100^{\circ} \mathrm{C}$. But also is known that water form the sea, rivers, pools, etc boils or enters gaseous phase in a constant way, turns into clouds and the whole cyclical process is known.

How do all this liquid evaporate if the transformation takes place at environmental temperatures on Earth $\left(-20^{\circ}\right.$ $\mathrm{C}$ to $50^{\circ} \mathrm{C}$ ) and never reach $100^{\circ} \mathrm{C}$ ? The answer is in not to confuse evaporation with boiling. Water evaporation can be produced at almost every temperature between 0 and $100^{\circ} \mathrm{C}$ under atmospheric pressure.

In evaporation, water molecules which acquire kinetic energy enough can escape form other's molecules attraction and reach the atmosphere. Logically, the more the system temperature is, the higher portion of molecules which escape they are.

Evacuation system through transporter bands presents two principal disadvantages. The first one consists of not be able to use normal transport bands made of gum, because mud at high temperatures would corrode them, and the second one consists of the space the take.

Other way for mud's evacuation mad to be found, which would take less busy floor surface, and it was here where the idea of using an Arquimedes screw at almost vertical position., that later will see it make possible a growth in drying efficiency, being the newer part of this investigation.

\section{A. Dehydration oven description.}

Basically it is a place which will have a radiant ground heating system.

Dehydration oven will have will have opening for mud entrance. Other opening will be required too at the top, with a vapour extractor, that is where this vapour will be driven to a conduct which belongs to an evacuation system for such vapour, that can be used for other energetic applications.

A turbine could be placed in escape system for electricity generation, that can be profitable since, as it could be deduct from entering and leaving volumes data to the dehydrator, that will be seen later, it will be evacuated a water of great volume about $80 \mathrm{~m}^{3}$ per day, that once turned into vapour they will give us a volume under a pressure very interesting for electricity generation by the turbine.

Oven must be thermically isolated, to prevent any kind of loss.

B. Initial data for heating and dehydration of mud into the oven.

Although the mud entrance to the current centrifugator is a bit lower, it will be upgraded supposing an amount of $100 \mathrm{~m}^{3} /$ day, with will be operating even under days with a high quantity of mud, and also it is gotten to have a dryness a bit higher than calculated in medium days and in valley days.

Initial data:

- Quantity of entering mud to the dehydrator: 100 $\mathrm{m}^{3} /$ día

- $\%$ dried matter in the dehydrator entering mud: $4 \%$

- $\%$ dried matter in the dehydrator proceeding mud: $20 \%$

- Current costs of dehydration:
○ Electrical Energy: 5.77 €/TDM (*)
○ Polielectrolite: $48.56 € / \mathrm{TDM}$
- Handling people: $14.38 € /$ TDM
- Fixed expense:

- Devices maintenance and civil handwork: $4.59 € / \mathrm{TDM}$

- Devices amortization and civil handwork: $19.76 € / T D M$

Total fixed expenses: $24.35 € / T D M$

Total current expenses: $93.06 € / T D M$

(*) TMS $=$ Tons of dried matter. 
- Dehydrated mud picking up containers capacity: $7 \mathrm{~m}^{3}$

- $\%$ amount in every container (aprox.): $93 \%$

- Improved volume in every container (aprox.): $6.5 \mathrm{~m}^{3}$

- Number of used containers every day: 3

For thermical drying we must take into account the following data too:

- Temperature for mud dehydration: $95^{\circ} \mathrm{C}$

- Entering dehydrator mud average temperature: $20^{\circ} \mathrm{C}$

C. Initial alternatives and results for heating and dehydration of mud into the oven.

Firstly, will be detailed only the alternatives that take into account that heat transfer by radiant ground of the different phototermical systems for water evaporation.. After, working on one of these alternatives, the evacuation-reheating system will be used, intervening Arquimedes screws mentioned previously..

\section{1) Alternative 1}

Firstly we thought on a system in which were improved the current dehydrator cover surface. To make it possible, a phototermic system was devised with the following characteristics:

- Solar collecting area: $126 \mathrm{~m}^{2}$

- Accumu lation volume : 50001

Results are exposed in table 1, and succes sfully in the following tables, obtained with optimum orientation and inclination of the solar collectors in Melilla City $\left(\right.$ Orientation $=0^{\circ}($ South $)$; Inclination $\left.=45^{\circ}\right)$.

As you can see, contributions and requests are calculated per months, and these needs are divided reasonably in every day, so we will have a request of $234472 \mathrm{kWh} 31$ days months, $226917 \mathrm{kWh}$ for 30 days months and finally $211778 \mathrm{kWh}$ on February.

Solar contribution is exactly calculated for every month in the projected station of Melilla, because for every geographic zone, logically, radiation and incidence parameters are different. We can take notice of different contribution for every month.

\begin{tabular}{|c|c|c|c|c|}
\hline $\begin{array}{c}\text { Available } \\
\text { radiation } \\
(\mathrm{kWh})\end{array}$ & $\begin{array}{c}\text { Supplied } \\
\text { useful } \\
\text { solar } \\
\text { energy } \\
(\mathrm{kWh})\end{array}$ & $\begin{array}{c}\text { Process } \\
\text { request } \\
\text { for 100\% } \\
\mathrm{MS} \\
(\mathrm{kWh})\end{array}$ & $\begin{array}{c}\text { Requested } \\
\text { energy } \\
\text { using solar } \\
\text { energy }(\%)\end{array}$ & $\begin{array}{c}\text { System } \\
\text { efficacy } \\
\text { coefficient } \\
(\%)\end{array}$ \\
\hline 329722 & 270652 & 2760750 & 9.8 & 82.1 \\
\hline
\end{tabular}

Table 1. Alternative 1 Results.

Solar collection per $\mathrm{m}^{2}$ of collector: $2148 \mathrm{kWh} / \mathrm{m}^{2}$ year Avoided $\mathrm{CO}_{2}: 81196 \mathrm{~kg} /$ year $(*)$

(*)Source $\mathrm{kg} /$ year avoided $\mathrm{CO}_{2}$ : EMEP/CORINAIR Atmospheric Emission Inventory Guidebook (SNAP-97)

Using this installation, very high efficacy coefficients are reached, but in absolute meaning, energy production is not enough for claims of this study to treat of changing totally current dehydration system for this one.

However, it could be taken into account this installation, as it was said and reported before, to complement centrifugation process which has been doing until now.in the station of Melilla, because it would increase mud dry matter easily and cheaply.

It is very important the amount of $\mathrm{CO}_{2}$, whose emission is avoided to the atmosphere, that in this installation exceeds 80 tons per year.

Solar production: $270652 \mathrm{kWh}$

Conventional energy cost: $0.12 € / \mathrm{kWh}$

Annual savings gotten using conventional energy for thermic dehydration: $32478.24 €$

\section{2) Alternative 2}

We also thought about a total possible dehydration, in other words, to leave resulting mud at $100 \%$ (a bit lower on December and January) of dried matter that, in many cases, it would be possible to use ceramics industry; About this many experiences have been carried out using other kinds of matters and energies in many places, with very interesting results. A photothermic system have been devised with the following characteristics::

- Solar collecting area: $2700 \mathrm{~m}^{2}$

- Accumulation volume : 200001

- Orientation $=0^{\circ}$ (South)

- Inclination $=45^{\circ}$

\begin{tabular}{|c|c|c|c|c|}
\hline $\begin{array}{c}\text { Available } \\
\text { radiation } \\
(\mathrm{kWh})\end{array}$ & $\begin{array}{c}\text { Supplied } \\
\text { useful } \\
\text { solar } \\
\text { energy } \\
(\mathrm{kWh})\end{array}$ & $\begin{array}{c}\text { Process } \\
\text { request } \\
\text { for 100\% } \\
\mathrm{MS} \\
(\mathrm{kWh})\end{array}$ & $\begin{array}{c}\text { Requested } \\
\text { energy } \\
\text { using solar } \\
\text { energy }(\%)\end{array}$ & $\begin{array}{c}\text { System } \\
\text { efficacy } \\
\text { coefficient } \\
(\%)\end{array}$ \\
\hline 8243056 & 2713152 & 2760750 & 98 & 32.9 \\
\hline
\end{tabular}

Table 2. Alternative 2 Results.

Solar collection per $\mathrm{m}^{2}$ of collector: $1005 \mathrm{kWh} / \mathrm{m}^{2}$ year Avoided $\mathrm{CO}_{2}: 813946 \mathrm{~kg} /$ year $(*)$

(*) Source $\mathrm{kg}$ /year avoided $\mathrm{CO}_{2}$ : EMEP/CORINAIR Atmospheric Emission Inventory Guidebook (SNAP-97)

As someone could verify, system efficacy coefficients are much lower in this installation than in the other one. It is due to the bigger an installation is, the smaller profits are gotten, due to loss by connection between collectors (two connected collectors will generate less of double of energy than only one collector), of a greater fluid course, etc.

Amount of $\mathrm{CO}_{2}$ takes now a special relevance, whose emission is avoided to the atmosphere, ant using this installation its amount is greater than 813 tons per year.

The more important problem of this installation in the busy surface quantity, that in the purifier station of Melilla, in which our study is based, it would be unfeasible its implantation due to current lack of available surfaces. 
Solar production: $2713152 \mathrm{kWh}$

Conventional energy cost: $0.12 € / \mathrm{kWh}$

Annual savings gotten using conventional energy for thermic dehydration: $325578.2 €$

\section{3) Alternative 3}

As third alternative we thought about a space feasible installation, in which could be placed all the collector on installations buildings tops, with a low cost related with purifier station cost, and which be able to get an acceptable percentage of dried matter. For this installation we devised a photothermic system with the following characteristics:

- Solar collecting area: $504 \mathrm{~m}^{2}$

- Accumulation volume : 200001

- Orientation $=0^{\circ}$ (South)

- Inclination $=45^{\circ}$

\begin{tabular}{|c|c|c|c|c|}
\hline $\begin{array}{c}\text { Available } \\
\text { radiation } \\
(\mathrm{kWh})\end{array}$ & $\begin{array}{c}\text { Supplied } \\
\text { useful } \\
\text { solar } \\
\text { energy } \\
(\mathrm{kWh})\end{array}$ & $\begin{array}{c}\text { Process } \\
\text { request } \\
\text { for } 100 \% \\
\mathrm{MS} \\
(\mathrm{kWh})\end{array}$ & $\begin{array}{c}\text { Requested } \\
\text { energy } \\
\text { using solar } \\
\text { energy }(\%)\end{array}$ & $\begin{array}{c}\text { System } \\
\text { efficacy } \\
\text { coefficient } \\
(\%)\end{array}$ \\
\hline 1252889 & 838437 & 2760750 & 30 & 66.9 \\
\hline
\end{tabular}

Table 3. Alternative 3 Results.

Solar collection per $\mathrm{m}^{2}$ of collector: $1.664 \mathrm{kWh} / \mathrm{m}^{2}$ year Avoided $\mathrm{CO}_{2}: 251531 \mathrm{~kg} /$ year $(*)$

(*) Source $\mathrm{kg} /$ year avoided $\mathrm{CO}_{2}:$ EMEP/CORINAIR Atmospheric Emission Inventory Guidebook (SNAP-97)

Using this option, a $30 \%$ of annual energy necessary to dehydrate $100 \%$ of mud is obtained.

We must stand out again the amount of $\mathrm{CO}_{2}$, whose emission would be avoided to the atmosphere, in fact we are talking about over 250 tons per year.

Someone could think, taking into account this amount of produced energy, a very liquid mud will be gotten, with a very low percentage of dried matter, but it is not true. The main constituent of mud is water, being so, this water has a great influence on the amount of necessary energy for dryness or dehydration of mud and for this reason is important to know the different shapes in which we can find it. This high humidity level of mud is divided into two classes or categories: free humidify and bind humidify. Free humidity is not associated with solids that are found in mud, and it is removed easily. Bind humidify is classified by Tsnag and Vesilind into three types: interstitial, superficial and chemically bind. Balance between free humidify and bind humidify is very important in mud dehydration.

Coakley and Allos studied through thermigravimetric curves the drying features of some mud (in these curves was represented the loss of water weight at constant temperature).The curves shows that the water's loss during thermic drying follows three stages: in the first stage the drying velocity or water's loss is constant and the two following stages in which drying or evaporation velocities decreases in different ways. Free humidify constitutes the greater part of mud and can be considerate that thermodynamically it behaves like pure water. This water can be removed by thickness or conditioning.

Bind humidify represents a little portion of total water contained in mud, but its mass is higher than solid part of mud. It does not behave like pure water. Of its variants we can indicate: interstitial humidify is what is removed in the first period of dryness velocity decreasing method and this water is bind to clot structure by superficial tension, turning into free humidify if clot is destroyed, this humidify is removed by pressure. Superficial humidify is removed in the second period of velocity diminution, water is bind to particles surfaces by absorption and can be removed by mechanical dehydration. Contrarily to interstitial humidify, in which water can move and erase when physical banishment disappears, in superficial humidify case water can not move so easily because it is joined to solid particle surface. Chemically bind humidify is fixed to the solid by chemical unions, being necessary an energy source for their separation, generally thermical energy or through conditioning process.

Therefore, at the same temperature, the 'first evaporation' of a piece of mud takes place quickly, because it has many free water, and with the supplied energy in this installation we will get $15-20 \%$ of dried matter in the resulting mud.

Solar production: $838437 \mathrm{kWh}$

Conventional energy cost: $0.12 € / \mathrm{kWh}$

Annual savings gotten using conventional energy for thermic dehydration: $100612.4 €$

Investment cost (including tax): $605808 €$ (without subventions)

Using current financiering and subventions given by IDEA :

Initial payment of $4 \%$ total investment plus tax $(121161.6 €)$

$26 \%$ subvention of total cost at lost funds $(157510.08$

$€)$

$70 \%$ of financed investment with EURIBOR - $2.5 \%$

(327136.32€)

From this point, this investigation will explain widely the improvement of alternative 3 , since, as we explained before, due to space reasons, cost and efficiency, is the most appropriated and the most fit to dehydrator needs that is being our reference (Melilla) to this study.

\section{4) Alternative 4: Initial Alternative 3 optimization.}

As the dryness reached in the described oven (15-20\%) is not very high, the way of increasing the dry matter percentage was searched.

Firstly, it seems to be clear that the most recommendable is to keep the mud inside the oven the largest time as possible, for this reason, we could chose a continuous process or a portion-divided process and we finally chose a portion-divided process because it was the most logical 
solution. In this process mud mass keeps inside the oven for a limited time without entering more mud until the previous one is completely out.

The operation consists of empting a complete amount of mud estimated for every portion inside the drier chamber. Once inside, all the mud that must be dried, the entrance will be closed and the mud inside the chamber is started to get moved using processes that will be more detailed later on, to expose the mass themically.

For evacuating dehydrated mud, as it was said before, an Arquimedes screw will be used that takes less room than a transporter bands system.

Screw generatrix is not a straight line but a semiellipse like the shown in figure 1 to have pace capacity without have to use any kind of enveloping box, besides to transmit heat, like will see later on.

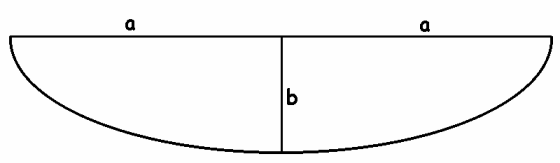

Figure 1. Arquimedes screw generatrix.

Arquimedes screw must be inclined a certain angle for mud's elevation and besides, as it will be convenient that elevation would be as slow as possible for keeping the mud in contact with the steel which will give it heat for a greater evaporation, it will be endowed with two helix for collect double quantity of mud in the same evolution, decreasing so the velocity to the half.

We wanted to represent how it would be such screw (figure 2), and for this it has been modelled using Mathematica program.

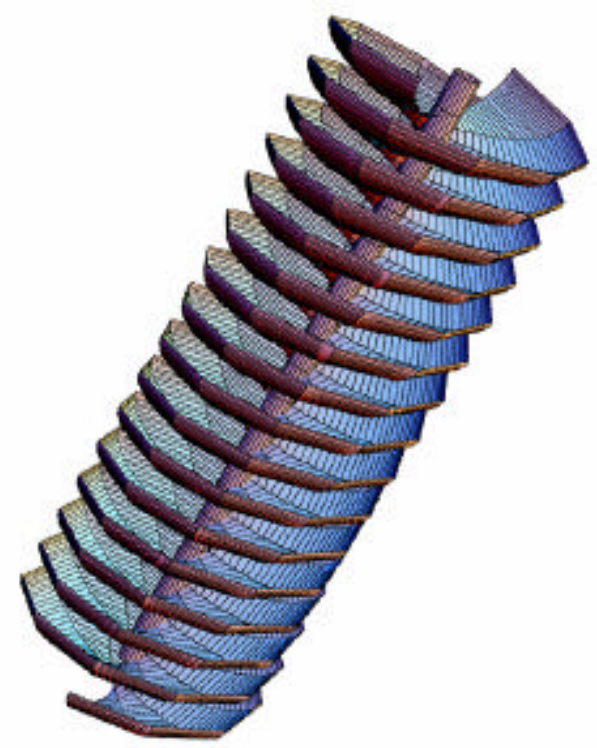

Figure 2. Double helix Arquimedes screw with semiellipctic generatrix
Immediately it represents the beginning of helix using the semiellipse as generatix in the screw's base (figure 3), trying to explain using a more graphical way the concept of double spiral rolled over the supporting bar.

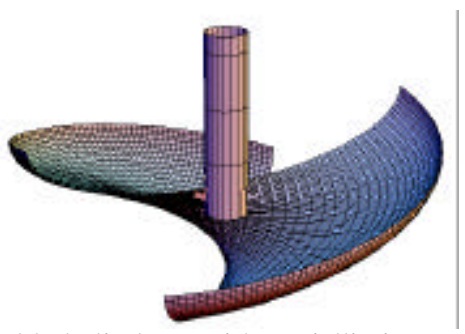

Figure 3. Double helix boot with semielliptic generatrix.

We can see clearly in the graphic the double entrance to the Arquimedes screw, which corresponds in all the development to double helix named before.

Although on the oven base mud is being dehydration to reach dried matter percentages said before, we thought to give a 'more personalized treatment' to mud to increase the dryness, applying heat to slim laminas of mud, what will produce a higher and faster increment of temperature for the lamina than for the rest of mud. It can be represented by the following graphics:

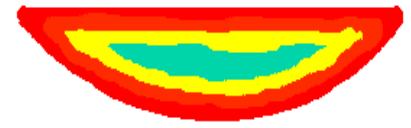

Figure 4. Mud mass heating.

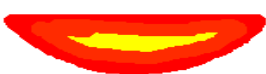

Figure 5. Mud lamina heating.

Mud's temperature is represented in decreasing order by the following colours: red, orange, yellow and blue. Looking at the drawing it is sufficiently clear why a little lamina heats more effectively than mud mass.

For this laminar heating a system has been invented which makes fluid that travels through tubular pipes of the radiant ground not to enter at surface level, but coming form up, driven though an Arquimedes screw made of inoxidable and hollow steel (figure 6).

For increasing the contact surface against hot steel, it was thought to use four Arquimedes screws with a smaller diameter instead of one with a bigger diameter for evacuation and heating in mud lamina.

Logically, the section given by screw generatrix semiellipse will not be improved completely since it is inclined to be able to elevate the mud, so to calculate the mud elevation velocity is required the surface of the figure. With this surface and knowing, as we know, the volume that will be elevated, we can obtain picking up mud lineal velocity, and using it, we can calculate screw spin velocity. 


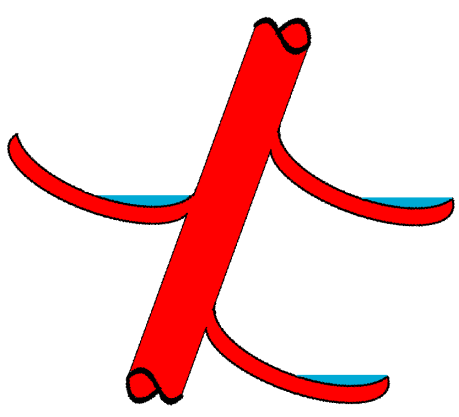

Figure 6. Contained mud in a screw section.

Now it remains to calculate the formula which give us blue zone surface of the figure, in other words, the evacuating volume surface, that will give us the lineal velocity and then we could get screw spin velocity. Being:

$\mathrm{a}=$ inclination angle of screw axis respecting to a vertical line, in radians $=$ ellipse greater semiaxis $\mathrm{b}=$ ellipse lower semiaxis

$\mathrm{S}=$ Searched surface (represented by blue colour in figure 6)

The following formula was obtained:

$S=a b\left(\frac{\pi}{4}+\frac{1}{2} \operatorname{arcsen}\left(\frac{2 b^{2}}{b^{2}+a^{2}(\operatorname{tg}(\alpha))^{2}}-1\right)-\frac{a b t g(\alpha)}{b^{2}+a^{2}(\operatorname{tg}(\alpha))^{2}}\right)$

Formula (1) is being deduced for making easily possible modifications of screw axis inclination and ellipse $(\mathrm{a} / \mathrm{b})$

About this, we must say that it has been supposed an inclination angle for the screw of $30^{\circ}$ respecting to a vertical line, greater semiaxis length of generatrix ellipse is $2 \mathrm{a}=42 \mathrm{~cm}$ and lower semiaxis length is $\mathrm{b}=7 \mathrm{~cm}$.

Using these data we will get a picking up section equal to $13.3177 \mathrm{~cm}^{2}$.

We could think about a very small surface and heat form the rest of screw surface is being wasted, but we must take into account that mud move in every spin on the whole semielliptic surface, and a eccentricity change, making a/b lower, what provide us a bigger picking up surface, would produce a lower heating effect since transported mud lamina would be fatter. Exists the possibility of reducing screw inclination too, but this rejected immediately since there would be problems for mud elevation.

As it was explained before, is not convenient to leave mud on the bottom oven because emitted heat would not be improved to heat uniformly the whole mud mass. Therefore it is important to think about a mud movement or agitation system and it seems to be obvious, since we get ready 4 screws, those must be taken charge of moving mud mass.

It is clear that moving the screws it will produce a mud elevation, and consequently mud evacuation, target not desired until completing estimated time in every portion of mud, that is the reason why we thought firstly in a spin reversible system for screws, in other words, spin in a sense for elevation and when we need to use screws as agitator, spin in the other sense, not producing mud picking up. However, it would be producing a mud mass heating, and our lamina heating devised during mud elevation would not be produced unless it occurs mud evacuation to let other portion enter the screw. Due to this we ought to think about other system which makes mud elevate constantly through the screw not producing its evacuation. Four screws elevated mud is thrown, when it reaches upper boundaries, into a hopper which only works as funnel to drive mud to an evacuation channel placed under the hopper. The found solution is simple: it has to be done a telescopic evacuation channel, placed in its more extended position when mud is required to be evacuated from dehydration chamber, and placed in its less extended position when it is not required to be taken out, falling the mud again to oven base. We could get using this process a water faster evaporation and, every time mud falls from the other upper edge of screws to the dehydrator chamber ground, it would be a bit more increased the dried matter percentage of total manipulating mass.

After all, two heating methods are being applying to mud constantly: the first one, heating the whole mud mass through radiant ground and the second one, heating mud laminas supplied by elevators screw surface

It has been estimated that using this system mud dryness percentage will be increased a $10 \%$, to carry it from a 15 or $20 \%$ of dried matter, calculated in proposed alternative 3 , till a 25 or $30 \%$ that are more convenient values, taking into account that using current centrifugator of purifier station of Melilla, it reports an efficiency of $20 \%$ of dried matter. With this dried matter percentage we could think even about remove the usage of any of the diary containers used to transport dehydrated mud, having now 2 containers of 3 containers we had before, getting some economic saving.

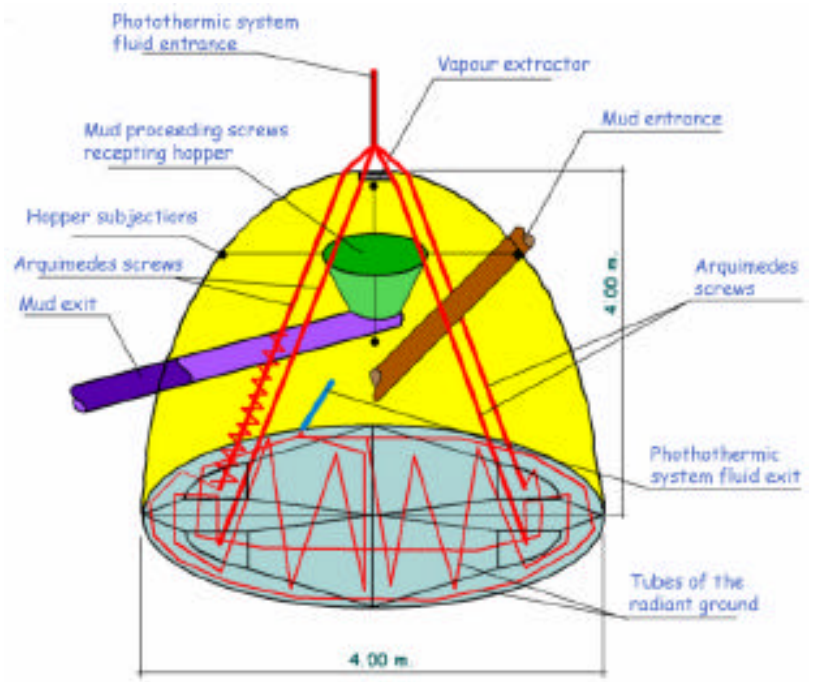

Figure 9. Devised dehydration chamber graphical scheme. 
Summary of devised new system functioning:

Mud mass reception: For the case of Melilla purifier, whose contribution to dehydrator is considered by 100 $\mathrm{m}^{3} /$ day, it has decided to carry out the process into 8 lots of $12.5 \mathrm{~m}^{3}$ every one, with a endurance of 3 hours by each lot.

Mud heating: According to oven dimensions, the height that mud will reach inside the chamber will be $1.4 \mathrm{~m}$ approximately. This mass will be heated due to the given heat by the radiant ground and, at the same time that it is been elevated by Arquimedes screws, it will produce a more effective heating, that is called "laminar", due to the given heat by the stainless steel surface which contains the heat driver fluid. During this phase, evacuation channel, which is telescopical, will keep recluse, the entrance and exit of mud will keep closed and the vapour extractor will keep working.

Mud evacuation: Depending on the screw turning velocity, this phase will have a higher or lower endurance, which is why in the 3 hours period marked for each lot, evacuation will have to start on time to get all the mud from the dehydrator chamber and so be able to get the new lot's mud.

As it is been calculated the double lamina (thanks to the double helix) recluse by each revolution, (13'32 $\mathrm{cm}^{2} \times 2=26^{\prime} 64 \mathrm{~cm}^{2}$ ) and depending on turning velocity we want to supply, it will be possible to know exactly in which instant the evacuation telescopical channel will have to be laid out for not to redrive the mud to the oven's base, but it is ejected from it to start with chamber's casting.

Relating to economics considerations, we will treat again alternative 3 ones:

In these economic considerations, we have compared produced energy prize $(0 €)$ and the prize that we would have to pay for the same amount of conventional energy for a thermical drying (100612.4 €). Now, we will see savings respecting to the actual annual expenses for dehydration that is taking place in the purifier station of Melilla. To calculate annual savings, we take again initial data:

Entering dehydrator mud: $100 \mathrm{~m}^{3} /$ day

$\%$ DM in entering dehydrator mud: $4 \%$

$\% \mathrm{DM}$ in proceeding dehydrator mud: $20 \%$

Current dehydrator costs :

Electrical energy: $5.77 € / \mathrm{TDM} \quad(*)$

Polielectrolite: $48.56 € / \mathrm{TDM}$

Handling people: $14.38 € / \mathrm{TDM}$

Fixed costs :

Devices maintenance and civil handwork: 4.59 €/TMS

Devices amortization and civil handwork: 24.35 €/TMS

Total current expenses: $93.06 € / \mathrm{TMS}$

(*) $\mathrm{TDM}=$ Tons of dried matter.

Taking this into account we can deduce the amount of dried matter obtained form purifier station: 4 tons per day, and annually it will be 1460 tons.
It is interesting to talk about exploitation and maintenance expenses, since once produced the devices total amortization, that is what will mark definitive difference, because using the proposed system the maintenance is almost despicable and energy expenses, as correspond to a photothermic system, are nulls. Only would be a little cost that is the electricity which feeds motors that make working the screws.

\begin{tabular}{|c|c|}
\hline \multicolumn{1}{|c|}{ Concept } & Cost \\
\hline Electrical energy & $5.77 € / \mathrm{TDM}$ \\
\hline Polielectrolite & $48.56 € / \mathrm{TDM}$ \\
\hline Handling people & $14.38 € / \mathrm{TDM}$ \\
\hline Devices maintenance and civil handwork & $4.59 € / \mathrm{TDM}$ \\
\hline Total & $73.30 € / \mathrm{TDM}$ \\
\hline
\end{tabular}

Table 7. Exploitation and maintenance costs.

Annual exploitation and maintenance expenses :

$$
1460 \times 73.30=107018 €
$$

Relating to the investments chapter, alternative 3 costs have to be taken into account and add it screws cost, because they must be elaborated expressly for this work and motors that move them. For screws we chose an stainless steel AISE-304 of $2 \mathrm{~mm}$ thickness, whose properties are very suitable for the kind of job that it is going to be realized. The budget for one screw of this material is estimated in $18000 €$, cost that could be decreased for a greater request (for this project are required four screws). Motors and electrical installation cost is around $15000 €$. So we must add these amounts to the initial investment $605808 €$, that has a cost of $87000 €$ between motors and screws and subtract $157510 €$ from subvention, getting a total cost of $535298 €$.

With all these data, we can affirm amortization of all the system will be done for a period between 6 and 7 years, and from this moment, mud dehydration would be almost free.

\section{Conclusion}

This study demonstrates that with an imaginative, thought and reasoned position, you can get a high efficient use of the Clean Energy (in this case the photothermic) for the dehydration of mud in purifier stations, getting a great saving, so much in the economic environment, like in the environmental one, avoiding great quantity of emissions from $\mathrm{CO}_{2}$ to the atmosphere.

Anyhow, it is better a system that combines mechanical dehydration and a posterior thermical dehydration. It is estimated that the two system working (the existing one of mechanical dehydration by centrifugator and the new one of thermical dehydration, devised in this study) one following the other one, and with a cremation station which provides the biomass heat (dehydrated mud, let us remember that in this case it has a PCI of $3600 \mathrm{kcal} / \mathrm{kg}$ of dried matter) to the thermical driying process, dried matter percentages could reach 60 or even $70 \%$. 


\section{Acknowledgement}

We introduce our grateful for VIESSMANN, S.L. for its support partly of the financing and for Juan Manuel Rubio (responsible of Photothermic Energy of VIESSMANN, S.L.) for his calculation of the collectors.

Our grateful too for:

- Área de Ingeniería Eléctrica de la Universidad de Granada

- Aznar Dols, Fernando

- Balbuena, Juan Pablo

- González Rodelas, Pedro

- Hontoria García, Ernesto

- Miragaya García, Gonzalo

- Nofuentes Ramírez, Susana

- Odeh, Suhail Musa

- Puyou Morales, Encarna

- THEIMA, S.L.

- TRATAGUA, S.A.

\section{References}

[1] Electrical Engineering Area of University of Granada. Photothermical Energy Notebooks.

[2] Arundel, J. Black Waters and Industrial Effluents Treatment. Ed. Acriba.

[3] Hontoria García, E. and Zamorano Toro, M. Fundamentals of Urban Residual Handling. College of Engineers of Roads, Channels and Ports.

[4] Jones, J. B. Thermodynamic Engineering. Ed. Prentice Hall Hispanoamericana.

[5] Long, C. A. Essential Heat Transfer. Ed. Longman. 